\title{
Eccrine Carcinoma
}

National Cancer Institute

\section{Source}

National Cancer Institute. Eccrine Carcinoma. NCI Thesaurus. Code C27255.

An adenocarcinoma with eccrine differentiation arising from the sweat glands. It includes the following subtypes: ductal eccrine adenocarcinoma, papillary eccrine carcinoma, and eccrine porocarcinoma. 